\title{
Quality-of-life as chronotopefication and futurization: Subsistence consumer experiences in India
}

\section{Sujit Raghunathrao Jagadale ${ }^{1}$ Djavlonbek Kadirov ${ }^{3}$}

Himadri Roy-Chaudhuri $^{2}$ |

WILEY \section{Djavlonbek Kadirov}

\author{
${ }^{1}$ Faculty of Marketing, Xavier University \\ Bhubaneswar, Bhubaneswar, India \\ ${ }^{2}$ Faculty of Marketing, XLRI Xavier \\ School of Management, Jamshedpur, \\ India \\ ${ }^{3}$ Faculty of Marketing, School of \\ Marketing and International Business, \\ Victoria University of Wellington, \\ Wellington, New Zealand

\section{Correspondence} \\ Sujit Raghunathrao Jagadale, Faculty of \\ Marketing, Xavier University \\ Bhubaneswar, Bhubaneswar, India. \\ Email: sujit@xub.edu.in
}

\begin{abstract}
In the poverty-ridden settings in neo-liberal India, we explore how subsistence consumers construct their quality-of-life (QOL). Drawing on the concepts of chronotope and futurization, we posit two additional dimensions of subsistence consumers' construction of QOL namely, chronotopefication and futurization. Our findings suggest that chronotopefication and futurization are defining processes of subsistence consumers' construction of QOL perceptions; their sacrifices, efforts, and costs, however painful they may be, would be perceived as QOL enhancing from the prism of chronotopefication and futurization; and subsistence consumers chronotopize and futurize QOL for the whole extended household within the intergenerational temporal space by focusing on stable input-outcome pathways. Based on the evidence, we propose QOL as chronotopefication and futurization framework (QOL-CFF). The framework suggests that subsistence consumers construct QOL as chronotope building, futurized and having a symbolic effect. They consider current agonies as a foundation for future building.
\end{abstract}

\section{K E Y W O R D S}

quality-of-life, subsistence consumers, subsistence marketplaces 


\section{1 | INTRODUCTION}

A mother and her two children have died within the first week of Sept 2018 in Uttar Pradesh (India) allegedly of hunger and malnutrition... The family belongs to the extremely poor Musahars, listed as Scheduled Castes (the lowest cast group). Visuals from the village and the family's home tell a story of extreme poverty... The family had a ration card (the targeted public distribution system, TPDS that subsidizes food), but there seems to be no trace of any food in the one-room house" (NDTV 2018).

Globally, a majority of consumers live in societies underscored by subsistence marketplaces (Viswanathan and Rosa, 2007; Venugopal and Viswanathan, 2017). Research on subsistence marketplaces adopts "a bottom-up approach that aims to build from a microlevel understanding of individuals and communities in subsistence contexts rather than adopting a priori theoretical stances" (Venugopal and Viswanathan, 2017, 342), while at the same time focusing on wellbeing outcomes for subsistence consumers as part of its broader research program (Viswanathan, 2017; Viswanathan et al., 2019). Responding to Viswanathan et al.'s (2019) call for a nuanced understanding of subsistence consumers' lived experiences of well-being, this research offers unique theoretical lenses (i.e., QOL-CFF Framework, to be discussed in the subsequent sections) for exploring extremely impoverished consumers' well-being experiences.

The plight of consumers living in absolute poverty involving excessively harsh life conditions on a global scale needs a renewed attention by consumer researchers (Hill and Adrangi, 1999; Hill, 2002; Hill and Gaines, 2007; Martin and Hill, 2011; Chaplin et al., 2014; Farrell and Hill, 2018; Schembri and Ghaddar, 2018; Chang, 2019; Hill, 2019). This task is extremely important because it is becoming evident that the global trends of hunger and malnutrition, indisputable proxies of extreme poverty, are expected to further increase in the future (FAO, 2018). Specifically, the conceptual and empirical perspectives on quality-of-life (QOL) of extremely impoverished consumers living at a cusp of existence need immediate attention. In India, such consumers are called subalterns who represent impoverished, mute, marginalized, and unprivileged strata of the population living at the fringes of society and consumption culture (Spivak, 1988; Lal, 2001; Vikas et al., 2015). In fact, these people represent those layers of population whose "voices" have not been systematically "heard" (Viswanathan, 2017). On the complex multidimensional continuum ranging from survival to transformation (Venugopal and Viswanathan, 2017), subalterns would be concentrated about the survival edge of the continuum.

A number of consumer research scholars studied how renewed market dynamics influence consumption in India (Baker and Palmer, 2006; Varman and Belk, 2008; Varman and Costa, 2008; Viswanathan et al., 2009; Askegaard and Eckhardt, 2012; Eckhardt and Humaira, 2012; Varman and Belk, 2012; Jagadale et al., 2018; Varman and Devi, 2018). Several researchers focused on subaltern consumers in the context of health care (Varman and Vikas, 2007a; 2007b), marketization and marketing (Vikas and Varman, 2007; RoyChaudhuri, 2010b; Vikas et al., 2015), consumer behavior (Roy-Chaudhuri, 2010a; Jaiswal and Gupta, 2015), lack of freedom (Varman and Vikas, 2007a; 2007b), material culture (Varman and Belk, 2008), and public policy failures (Varman et al., 2012). Moreover, the recent literature in consumer studies situated the issues facing subaltern consumers at the nexus of consumption, morality, and governance (Khare and Varman, 2016, 2017; Belk and Ghoshal, 2017; Jagadale et al., 2018; Varman and Devi, 2018). However, what is missing from the literature is a 
focused attempt to explore and understand subalterns' QOL perceptions. The existing research on poor consumers' QOL so far investigated the impact of material resources (Veenhoven, 1991, 1995; Schyns, 2000; Biswas-Diener and Diener, 2001), primary goods (Rawls, 1971; Rawls and Kelley, 2001), capabilities (Sen, 1985; Nussbaum and Sen, 1993), and dignity (Nussbaum, 2011; Jagadale et al., 2018). These studies offer different solutions such as enhancement of economic capital, income, and other material endowments, primary resources such as democracy and justice, capabilities, functions and skills, and dignity-based social capital. The current study complements the existing QOL research by providing unique theoretical underpinnings to the previous explanations. Our interpretation of subaltern realities revealed that chronotopefication and futurization processes define the extent to which different types of capital (i.e., resources) impact QOL perceptions. We draw on Bakhtin's (1937) concept of "chronotope," time-space thematic structures in literary works, to explain subalterns' sensemaking concerning QOL. We define chronotopefication as the process of constructing QOL perception as a set of dynamic and interpenetrating chronotopes, the practice which involves the creative shaping of temporality. Besides, although there are different definitions of futurization (Pulver and Van Deveer, 2007; Sircova et al., 2019), here we refer to futurization as a specific type of chronotopefication process through which subalterns' imaginings of "positive future" contrasted to images of "negative past" drive their communal QOL perceptions and practices. This research shows that subalterns experience their life via the prism of chronotopefication and futurization, whereas their QOL perceptions emerge as ongoing dynamic construction and complex fusion of chronotopes arising as a combination of sociocultural spaces with temporal points. These processes enable subalterns to "bend" the otherwise linear flow of time by (a) compressing prolonged negative experiences into dense chronotopes, and (b) dwelling into or extending singular events experienced in a positive way. Moreover, we find that subalterns' QOL chronotopefication is augmented with futurization, that is, ongoing construction of vivid imaginings of future involving family members, extended family, and community. Anecdotal evidence indicates that people facing extreme hardship tend to use futurizing expressions such as "there's no future here," which represents an ideologically constructed chronotope (Crivello, 2015). In some instances, political ideologies focusing on minorities and marginalized groups tend to capitalize on the well-being structuring capacity of future focus via idioms such as "the future is ours" (Bowler and Segura, 2011).

This investigation contributes to the discipline of consumer studies in general, and the research stream of subsistence marketplaces specifically, by submitting that (a) chronotopefication and futurization are defining structural processes of subaltern consumers' construction of QOL perceptions; (b) subalterns' sacrifices, efforts, and costs, however painful they may be, would be perceived as QOL enhancing from the prism of chronotopefication and futurization; and (c) subaltern consumers chronotopize and futurize QOL for the whole extended household within the intergenerational temporal space. As predicted by Venugopal and Viswanathan (2017), our use of the bottom-up approach with its focus on lived experiences and in situ meanings of extremely impoverished consumers allows us to uncover the unexpected dynamics of well-being construction. To elucidate this process further, we first present the theoretical background of research on QOL perspectives in subaltern consumption milieus. Then, we present the current study's approach to collecting qualitative data and interpreting it. This is followed by the results of data interpretation. The final section presents the discussion of the results and the implications for marketing managers, scholars, and public policymakers. 


\section{QOL IN SUBALTERN MILIEUS}

\section{1 | Context: subaltern consumers in India}

Neo-liberal economic policies in India resulted in some paradoxes, some of which, in particular, concerns the QOL of subaltern consumers. On a macrolevel, the impressive growth rates of gross domestic product failed to trickle-in-the increase was observed in hunger, malnutrition, and disguised unemployment (Patnaik, 2016). The per capita availability of food grains declined throughout 1990-2014, while the real purchasing power of the working population deteriorated. 2019 Global Hunger Index puts India in the category "alarming” regarding food availability. Prices of essential services like education and health care increased due to privatization. In the last two decades, the country was shaken by 0.35 million suicides among farmers (Shrivastava and Kothari, 2014). As "leaping luxuries" in transitional economies strengthened (Belk, 1999), the situation of subalterns further deteriorated through the creation of "false illusion" (Kahneman, 1994). India has the highest proportion of the poor in the world. Despite the claims about the material progress made, the benefits of increased welfare have not reached many subalterns (Dreze and Sen, 2013; Patnaik, 2013).

Marketing scholars studied QOL issues of diverse, disadvantaged consumer groups (Carter, 1996; Hill and Dhanda, 1999; Love and Crompton, 1999; Bearden and Wilder, 2007; Ekici and Peterson, 2009; Nguyen and Nguyen, 2012; Sandikci et al., 2016; Backer and Weiler, 2018). The substantial scholarship was dedicated to exploring subaltern consumers and the impact of complex socioeconomic settings. These studies focused on the paradox of declining health care in the backdrop of improving private markets (Varman and Vikas, 2007a; 2007b), social hierarchies and marketization (Vikas et al., 2015), consumption behavior of subalterns (Jaiswal and Gupta, 2015), issues with freedom of subaltern consumers (Varman and Vikas, 2007a, 2007b), marketing of intoxicants to homeless children (Vikas and Varman, 2007), promotion of hedonism among subaltern consumers (Roy-Chaudhuri, 2010a), personal material aspirations and economism (Varman and Belk, 2008), public policy failures in subaltern marketing initiatives (Varman et al., 2012), and everyday life of subaltern consumers (RoyChaudhuri, 2010b). The extant literature manifests distinct and contesting perspectives of ideological positioning concerning the subaltern dilemma. Varman and Devi (2018) emphasized subaltern derealization, exploitation, and dehumanization, whereas Khare and Varman $(2016,2017)$ highlighted the exploitative role of state and market mechanisms (Varman and Devi, 2018). While Belk and Ghoshal (2017) argue that the subaltern quandary, that is, ever-deepening poverty at the time of overall economic growth, is exacerbated by several layers of cultural-caste based disadvantages, Jagadale et al. (2018) argue that the subaltern quandary cannot be solved by proposed BOP or market solutions, because these solutions paradoxically affirm the "subaltern" status which subalterns desire to flee from. Karnani (2017), professing ideological eclecticism, alludes to the important role of both public and private sectors in poverty alleviation. Researchers recognize that a variety of dynamic provisioning mechanisms are possible: self-provisioning, communal arrangement, social exchange, public goods, and market exchange (Dixon, 2002; Fisk, 2006; Kadirov, 2018). In Indian society, subalterns found themselves extremely vulnerable due to the state's gradual withdrawal from many aspects of communal provisioning, while the gap was filled by private markets (Kurien, 1994, 1995; Patnaik, 2006). 


\subsection{Perspectives of subaltern QOL}

QOL is a conceptually complex notion that gained prominence since the late 1960s. It comprises a material, relational, and cognitive/affective dimensions of human life (Diener et al., 1999; Wilkie and Moore, 1999; Burroughs and Rindfleisch, 2002; Cummins et al., 2003; Land et al., 2012). The concept is distinguished by the richness of conceptual possibilities (Nussbaum and Sen, 1993): what is implied by QOL varies depending on the concept's operationalization (Alborz, 2017). Moreover, the exact definition of the concept and the way it is used depends on research objectives and contextual factors (Kapuria, 2014). Several researchers investigated QOL issues related to disadvantaged and marginalized consumers (Carter, 1996; Hill and Dhanda, 1999; Love and Crompton, 1999; Bearden and Wilder, 2007; Ekici and Peterson, 2009; Nguyen and Nguyen, 2012; Sandikci et al., 2016; Backer and Weiler, 2018). Sirgy (2012) proposed three broad categories of QOL: psychological happiness (well-being linked to affect, hedonism, and emotions), prudential happiness (well-being underscored by subjective perceptions and life satisfaction), and perfectionist happiness (well-being that flows from eudemonia, virtuous fulfillment, human flourishing, and development). Other similar concepts that match this differentiation are a pleasant life, the engaged life, and the meaningful life correspondingly (Seligman, 2011).

Echoing the aforementioned classification, different theoretical positions underlie the conceptual perspectives on the QOL of subaltern consumers. The conventional approach to conceptualize QOL for impoverished and marginalized individuals emphasizes resources commanded by these individuals. Taking a sociological perspective, Veenhoven $(1991,1995)$ proposed livability theory suggesting income plays a significant role in the enhancement of QOL for the poor. According to this theory, even a marginal increase in income would allow the poor to meet their most substantial needs (Veenhoven, 1995; Schyns, 2000; Biswas-Diener and Diener, 2001). A similar but broader approach was advanced by Rawls, who envisioned the necessity of primary goods: income/wealth as well as rights, liberties, opportunities, justice, and self-respect (Rawls, 1971; Rawls and Kelley, 2001). Rawls postulated that individuals would strive to have more of primary goods to attain desired QOL. Amartya Sen (1985) took a distinct view, the capability approach, largely informed by welfare economics, that stood in stark contrast to the utility assumption (well-being is related to happiness, pleasure, desire fulfillment) and the opulence assumption (well-being relates to income, commodity ownership). These two assumptions are closely related to Sirgy's psychological and prudential happiness. Akin to perfectionist happiness, Sen's capability approach exposed the inadequacy of income as an indicator of good life, while suggesting that well-being should be seen as a combination of the functionings/doings of individuals and their capabilities (Sen, 1985). Functionings referred to what an individual may value doing/being such as adequate nourishment or self-respect, whereas capabilities were defined as individuals' capacity to realize those functionings (Sen, 1983, 1985; Dreze and Sen, 1989). Studies in positive psychology reflect a similar sentiment-QOL is contingent not only upon possession of material goods but also on experiences of hope, optimism, human rights, greater longevity, and equality (Diener et al., 2002; Bailey et al., 2007; Ciarrochi et al., 2015)—qualities that elude subaltern consumers. Some scholars note that the focus on nonmaterial resources is prominently absent from the studies of subaltern consumers (Ansari et al., 2012), except for a macromarketing inquiry by Jagadale et al. (2018). Moreover, in general, research highlights the limitations of material resources in improving QOL (Diener and Seligman, 2004; Roster, 2015; Lee and Ahn, 2016) while emphasizing the 
importance of social relationships, social capital, democratic governance, and human rights, that is, noneconomic predictors of well-being.

All in all, the existing research perspectives appear to emphasize the linear effect of various resources in QOL enhancement (Diener and Biswas-Diener, 2002). The linear effect assumption involves a presumption that an increase in a resource (e.g., material, primary goods, freedom, dignity, capability), in whatever form it may be, would lead to a proportional increase in QOL depending on the magnitude and importance of the resource under focus. This view underestimates the effect of symbolism, that is, the meaningfulness of QOL constructions within sociocultural space. Moreover, the prior research is outcome-oriented: the focus is on ensuring effective outcomes for the poor from the vantage point of a powerful actor (e.g., state, authority). This approach tends to be paternalistic. What is missing is a holistic approach geared to understand subaltern meanings and understandings of QOL (Day and Jankey, 1996), which may lead to a better understanding of ways through which subalterns could take control over the process of reform. Next, we elaborate on an alternative perspective of conceptualizing QOL for impoverished consumers that challenges entrenched assumptions. This perspective draws on a broad but not well-integrated research stream in the domain of QOL research that focuses on spatiotemporal (time-space) communal narrative constructions and the process of futurization that shape perceptions of well-being among subaltern consumers.

\section{$2.3 \quad$ QOL as time-space thinking}

The extant research shows that QOL is closely intertwined with spatial-temporal perceptions, that is, sociocultural thinking based on past, present, and future. Specifically, the existing research emphasizes linkages between well-being and perceptions of the future. Researchers argued that happiness, as a general feeling, is forward-looking, that is, it is future-oriented (Scheier and Carver, 1993; Hayborn, 2001). In particular, perfectionist happiness entails concepts such as eudemonia and personal growth, which are futuristic (Deci and Ryan, 2008; Sirgy, 2012). The proposed measures of perfectionist happiness focusing on human flourishing include items such as "I am optimistic about my future" (Diener et al., 2010). Moreover, researchers show that expected future satisfaction with life is an integral part of satisfaction with one's life as a whole (Sumner, 1996; Sirgy, 2012). Similarly, the construct of spiritual wellbeing includes one's feelings about settled versus unsettled future (Scott et al., 1998; Sirgy et al., 2010). Maintaining a view of a positive future, that is, optimism is found to enhance one's QOL (Scheier and Carver, 1993; Cummins and Nistico, 2002). From a macro perspective, personal views on community well-being comprise perceptions of future development (Baker and Palmer, 2006; Sirgy et al., 2010). Furthermore, the literature on hope focuses on how cognitive mechanisms of agency and pathways interact with future self-selected goals (Snyder, 2002; Snyder et al., 2002). Research shows that hope is positively correlated with life satisfaction and well-being (Bailey et al., 2007; Ciarrochi et al., 2015). Besides, this research emphasizes cognitively constructed pathways that link past to future or other way round.

In general, most researchers agree that views/understandings of future, and by implication understandings of temporality within cultural space, play a significant role in individuals' happiness perceptions. However, in these diverse scholarly perspectives and conceptualizations, time (past-present-future) perception is neither systematically examined nor conceptually integrated within a broader time-space framework of well-being. Although some research programs such as research on hope (Snyder, 2002; Snyder et al., 2002; Bailey et al., 2007; Ciarrochi 
et al., 2015) and optimism (Scheier and Carver, 1993; Cummins and Nistico, 2002) consider the impact of feelings about future (e.g., hope, optimism) on well-being or life satisfaction, these research streams appear to be mechanistic in treating time flow as uniform, symmetric and linear. Moreover, the prior research appears to be isolationist in keeping temporal and spatial phenomena separated as well as positivist in assuming that hope/optimism is conceptually separate from well-being. The perspective we take acknowledges such methodological differences submitting that, from the current research's perspective, "time" is an interpretive construction that is inherently fused into well-being perceptions. At this junction, there appears to be a lack of studies that position "time" as the dynamic and constructive element of QOL, specifically, in the context of subaltern consumers' well-being. In the extant literature, there appears to be no clarity regarding how time-space perceptions structure past or current QOL. Moreover, the impact of sociocultural and intergenerational dynamics is not well studied. The previous research focuses on an individual and his/her QOL perceptions. However, some research admits its communal character. For instance, a poor person's current well-being may well depend on the imagined success of their offspring in the distant future (Biswas-Diener and Diener, 2001).

Yet, we find a number of QOL theories that offer some insights involving time-space elements to explain how the subaltern group may form or structure their perceptions of well-being. Emphasizing stable cause-outcome patterns that persist from present into future, attribution theory of happiness predicts that QOL perceptions depend on the nature of agency feelings (Schwarz and Clore, 1983; Staats et al., 1995; Snyder, 2002): unhappy people tend to attribute failure or negative circumstances to their personality or agency while expecting this pattern to continue into future, while happy people tend to attribute failure or setbacks to temporary uncontrollable factors. Specifically, in agreement with Staats et al. (1995), the theory predicts that the poor would not dwell on their current situation per se to form their QOL perceptions. On the contrary, they would focus on minute positive events that they think are going to play out in the future. On the other hand, balance theory proposed by Sirgy (2012) predicts that disadvantaged people experiencing difficulties may balance current negative experiences out by maintaining strong expectations of future joy. This assumption is also linked to the notion of future discounting according to which difficulties of the present are necessary for the occurrence of a positive future (Sirgy, 2012).

Simsek's (2009) theory of ontological well-being includes past, present, and future dimensions. Simsek argued that the "future" is reified through emotions such as hope, anxiety, and optimism, as well as cognitive processes that form a future outlook for one's life. Hope appears to be a key concept in this context (MacInnis and De Mello, 2005; Gallagher and Lopez, 2018). Snyder et al. (2002) argue that people with high hope can visualize distant goals, believe that there are workable pathways to attain those goals, and also believe in their capabilities (agency), which enables them to follow these pathways. Biswas-Diener and Diener (2001) explored the satisfaction levels of pavement dwellers (poor homeless living on streets) in Kolkata, and to their surprise, found that their respondents appeared satisfied within specific life domains, although their general life satisfaction was negative. The authors attributed this gap to diverse, close social relationships that slum dwellers enjoy. Our re-reading of the case studies provided in Biswas-Diener and Diener's (2001) article revealed the use of a specific life-story chronotope. In other words, subalterns interpreted their QOL as something greater than themselves, something that goes beyond "the self." The respondents attributed their happiness, albeit very insignificant, to themselves participating in constructing pathways for their offspring's desired success in the future. Interestingly, these perceptions were neither about "present" nor self-oriented or egoistic, which most QOL researchers tend to assume when conceptualizing happiness. 


\subsection{The impact of the caste system}

Time perceptions are never sterile. Rather these are "contaminated" with sociocultural and ideological assumptions. The views of past, present, and future are structured by key cultural phenomena. Caste, as the unique and conspicuous feature of Indian society (Beteille, 2015), is the predominant factor in defining and maintaining the socioeconomic "hegemonic discourse" in Indian society. These hegemonic discourses underpin the complex foundation of subaltern stratification (Spivak, 1988) and associated material conditions (Deshpande, 2017). It is argued that the caste system is "a form of differentiation wherein the constituent units of the system justify endogamy based on putative biological differences which are semaphored by the ritualization of multiple social practices" (Gupta, 2015, 49). Hierarchy and hyper-symbolism are two properties of the caste system. Castes are (a) distinctively separated from each other in marriage, food consumption, and contact; (b) divided in terms of labor; and (3) ranked in terms of superiority/inferiority (Dumont, 1970). Hyper-symbolism refers to the discrete character of the caste perpetuated through a multiplicity of ritualized practices. Economic life is regulated by the caste system: subaltern caste groups are, hegemonically and systemically, excluded based on identities in modern markets (Thorat and Newman, 2015).

In India, market-based discrimination based on caste is ubiquitous (Weisskopf, 2004; Thorat et al., 2005). Subalterns are either excluded from entering the markets or selectively included without equal treatment (Thorat and Newman, 2015). It leads to "ghettoizing" of subalterns in some sense, like restricting them to some forms of employment not preferred by upper castes, which in itself tends to lead to ill-will, aversion, and desire to evade. Besides, it denies the subaltern the "dignity of physical labor" (Thorat and Newman, 2015; Jagadale et al., 2018), which results in the lack of appropriate incentives to optimally use resources. Deshpande (2017) postulated that in market-oriented economies, discrimination, and strong market orientation easily coexist and endure. She furthers that in the globalized and liberalized era, foreign (economic) interests tend to adapt to these conditions while perpetuating existing fault lines and patterns of inequality. The paradoxical situation arises when the caste system contributes to the perpetuation of hopelessness, inhibits pathways, and creates distrust within modern institutions. From a macro perspective, the traditional functioning of local marketing systems is underscored by justice perceptions as the main motivating force (Kadirov, 2018), that lead market actors to develop institutional trust that their efforts will eventually bear some fruit-not necessarily for themselves only, but for all. For a developing country, improvement in the QOL of the poor is linked to trust in these institutions (Ekici and Peterson, 2009). Market failure or problems mediated by the caste system such as injustice, limited access to opportunities, perpetual vulnerability, sabotaging effort-outcome links, and violation of dignity may negatively affect the longterm QOL of subaltern consumers.

\section{3 | INQUIRY METHOD}

\section{1 | Research context}

This investigation was conducted in the Mirzapur district of the north Indian province of Uttar Pradesh (UP). The region is situated in the Ganga belt, which is historically considered to be one of the most populous regions in the world. The district is one of the most underdeveloped districts of India (Mirzapur, 2019), with a population of around 2.49 million. Over $70 \%$ of its 
population lives in rural areas. Agriculture is the mainstay for livelihood as per the general pattern in India. The per capita state domestic product of Uttar Pradesh is INR 61,351, which is half of the national average of INR 126,406. In 2017 the province's per capita income (per annum) at current prices was INR 43,861 (\$630) against the national average of INR 103,219 $(\$ 1,500)$ (Press Information Bureau, 2017). Mirzapur hosts the carpet-making industry, which developed a negative reputation due to some reported incidences of bonded labor. Mirzapur is also distinguished with distress migration, that is, groups of unskilled and semi-skilled laborers shifting from the poor East to the Western industrial provinces of India.

\subsection{Inquiry approach and data collection}

With the theoretical underpinnings discussed in the preceding section in mind, we initiate a qualitative inquiry to explore the subjective experiences of subaltern consumers (Glaser and Strauss, 1967; Ahuvia, 2005; Batra et al., 2012). We focus on their cognitive construction of QOL with the following guiding research question: how do subaltern consumers form QOL perceptions, and what factors shape these perceptions? We follow the constructivist epistemological orientation that informs our choice of methods (Schwandt, 1994). From this orientation, we maintain that the participants face multiple, relativistic, dynamic realities, while their interactions with others shape the meaning of these realities (Lincoln and Guba, 1985; Guba and Lincoln, 1989; Creswell, 2013).

A total of 28 respondents were recruited using purposeful sampling that ensured the inclusion of respondents from disadvantaged and vulnerable consumer groups, including women, lower caste, and minority religion consumers (Goulding, 2005). Semi-structured in-depth interviews were conducted (McCracken, 1988; Silverman, 2006). In these interviews, the focus was on the respondents' life-stories, their understanding of happiness, QOL, and market participation. The interviews required a disciplined approach by the interviewers to maintain the utmost sensitivity to the cultural context. Also, the interviewing process involved extensive probing to delve deep into the issues under focus. The interviews lasted from 40 to $100 \mathrm{~min}$. The interviewers started interviewing by informing the respondents about the purpose of the study and sought their consent for participation and recording. Besides, the interviews were followed by informal discussions in informal settings to understand the context and nuances of their narratives better. These informal discussions were not recorded and transcribed, but they helped in the iterative and reflexive stages of this research. Willingness to talk to the researchers and share their experiences was the inclusion criterion as well, in addition to the criterion of purposeful selection mentioned above. The interviews were verbatim transcribed and translated (Poland, 2002; Davidson, 2009) from local language (i.e., Bhojpuri, a distinct dialect of the national language Hindi) into English (Table 1).

\section{3 | Data analysis}

Owing to its flexibility, we chose thematic interpretive approaches to code data and derived meanings (Strauss and Corbin, 1998). This method is essentially independent of theoretical and epistemological expectations and can be applied across a range of different approaches (Braun and Clarke, 2006). The search for meaningful themes helps to identify, analyze, and report observed patterns (i.e., themes) within qualitative material (Daly et al., 1997; Braun and 
TABLE 1 Profile of research participants

\begin{tabular}{|c|c|c|c|c|c|}
\hline Sr. no. & Pseudo-name & Gender & Caste category & Age & Profession \\
\hline 1 & $\mathrm{R} 1$ & Male & $\mathrm{OBC}$ & 27 & Agriculture/small shop \\
\hline 2 & $\mathrm{R} 2$ & Female & $\mathrm{SC}$ & 33 & Agricultural laborer \\
\hline 3 & R3 & Female & ST & 28 & Community mobilizer \\
\hline 4 & R4 & Male & $\mathrm{SC}$ & 20 & Student \\
\hline 5 & R5 & Female & $\mathrm{SC}$ & 30 & Agricultural laborer \\
\hline 6 & R6 & Female & OBC & 50 & Agriculture/animal husbandry \\
\hline 7 & R7 & Male & $\mathrm{OBC}$ & 55 & Agriculture/small shop \\
\hline 8 & R8 & Female & овС & 24 & Community mobilizer \\
\hline 9 & R9 & Female & SC & 20 & Community mobilizer \\
\hline 10 & R10 & Male & OBC & 30 & Small poultry farmer \\
\hline 11 & R11 & Female & $\mathrm{SC}$ & 35 & Agricultural laborer \\
\hline 12 & R12 & Male & SC & 38 & Shopkeeper \\
\hline 13 & R13 & Female & OBC & 35 & Tailor \\
\hline 14 & R14 & Male & OBC & 37 & Shopkeeper \\
\hline 15 & R15 & Female & $\mathrm{SC}$ & 25 & Agricultural laborer \\
\hline 16 & R16 & Female & $\mathrm{SC}$ & 30 & Agricultural laborer \\
\hline 17 & R17 & Female & $\mathrm{OBC}$ & 40 & Agriculture/community mobilizer \\
\hline 18 & R18 & Female & $\mathrm{SC}$ & 55 & Community mobilizer \\
\hline 19 & R19 & Female & SC & 40 & Community mobilizer \\
\hline 20 & R20 & Female & SC & 22 & Agricultural laborer \\
\hline 21 & $\mathrm{R} 21$ & Male & $\mathrm{OBC}$ & 35 & Agricultural laborer \\
\hline 22 & R22 & Female & SC & 37 & Agricultural laborer \\
\hline 23 & $\mathrm{R} 23$ & Female & OBC & 65 & Agricultural laborer \\
\hline 24 & R24 & Male & $\mathrm{SC}$ & 59 & Agricultural laborer \\
\hline 25 & R25 & Male & SC & 32 & Cattle rearing \\
\hline 26 & $\mathrm{R} 26$ & Female & NA & 55 & Domestic aid \\
\hline 27 & R27 & Male & SC & 45 & Agricultural laborer/cattle rearing \\
\hline 28 & $\mathrm{R} 28$ & Male & NA & 60 & Sweeper, an unskilled manual labor \\
\hline
\end{tabular}

Note: The interviewees' names are disguised. The caste category of the two participants (R26 and R28) is kept confidential.

Clarke, 2006). The process involves the identification of themes through coding and "careful reading and re-reading of the data" (Rice and Ezzy, 1999). We analyzed interview transcripts line by line and coded it. These codes were carefully studied to construct emerging themes. The technique of constant comparison was used to draw comparisons between emerging themes and the collected data (Glaser and Strauss, 1967). The analysis commenced with the transcript of the first interview. We used data matrices to guide our understanding and structuring of the codes. In doing so, we focused on the possible meanings of interview quotes. We used investigator triangulation, whereby researchers independently examined the phenomenon to establish 
the veracity of the interpretation. Besides investigator triangulation, prolonged engagement, thick description, and purposive sampling were used to establishing trustworthiness (Erlandson et al., 1993).

\section{$3.4 \quad$ Interpretive perspective}

To make sense of subaltern QOL perceptions, we employ Bakhtin's (1937) notion of "chronotope" as an interpretive approach. According to Bakhtin, the concept of chronotope, inspired by Albert Einstein's theory of relativity and constructed from the combination of chronos (time) and topos (space), refers to the structural characteristic of literary storytelling based on unique, localized, cultural, and myth-driven time-space interpretations. The use of the notion is inherently methodological (Wirtz, 2016) because it sensitizes the observer to individuals' narratives as the product of time-space perceptions (Bemong et al., 2010). In contrast to assuming time to be uniform, constant, linear, Bakhtin argued that time and space are inseparable as well as malleable, flexible, nonlinear (Johnston, 2002). In Bakhtin's (1981, 84) words, "Time, as it were, thickens, takes on flesh, becomes artistically visible (to human observation); likewise, space becomes charged and responsive to the movements of the time, plot and history." From this chronotope perspective, "time" is understood as an ideological and sociocultural construction, while "space" is seen as the fusion of social, dialogical, intergenerational, communal settings. In our interpretation, we distinguish between chronotope (i.e., the outcome of the interpretive process) and chronotopefication (i.e., the interpretive process). Our synthesis shows that QOL perceptions are the result of chronotopefication, which means that each specific QOL experience represents a sui generis chronotope.

\section{4 | INTERPRETIVE FINDINGS}

\section{1 | Subaltern plight: past-to-future chronotopefication}

Life has always been a struggle for me. I didn't have any education; from very early years of life, my mother made me carry milk to the local market. So, I couldn't go beyond Standard 4 in school. However, I can read and write in vernacular. I can also sign. I wanted to get educated and establish myself in life. I got married early. My husband and in-laws were abusive. My husband was a lazy, worthless fellow. But you can't neglect your husband. He is the source of your sustenance and security. I tried to serve them with the best of my abilities. But every day, I used to get beaten up. He kicked me, pulled my hair-I was beaten blue and black. My husband didn't care to go to work, and income was meager. We were made to live on the bare minimum, and often I used to have hot chilies mixed with water as food. You know it kills your hunger so well!!! I have two children with him. With practically no means to survive, I decided to kill myself. One early morning I walked up to the nearby railway track. That was a turning point in my life. So much of despair suddenly turned into an opportunity. I met Shailadi (a local woman). She saw me and could sense something was wrong. She came up to me and gave me a tight slap... my life turned from then on. Then Shailadi took me to a bag manufacturing factory, and I started working there (R26). 
R26's narrative is a typical life story of a subaltern. Through similar life stories, subalterns offer their take on life events, which are full of unexpected twists and turns involving the community, extended family, friends, and themselves. Subalterns, by telling their life stories, engage in active sense-making: their stories are situated within sociocultural space transformed by past-present-future stream of negative as well as positive events. In subalterns' attempts to makes sense of their life, we read chronotopefication-the process that we define as on-going dynamic construction of QOL perceptions as one's surrounding sociocultural space is pushed back and forth along the temporal dimension in an imaginative and transformative manner. In such movements, the perception of time is transformed as well, through twists and turns it takes when subalterns alternate zooming out (i.e., the macro view) with sudden zooming in (microevents). The chronotopefication process is evident in the narrative that starts with positioning R26's self-identity within a futurized vision of herself as an educated person with a secure income and more economic opportunities. This macro context provides meaning to her story of past struggles, extended to indeterminable past, constructed as the prolonged situation with nonexisting opportunities. The process of subaltern chronotopefication involves the construction of a chain of events leading to a critical temporal point, that is, some point of time, beyond which nothingness is preferred to the existence, or in other words, death is preferred to life. The microstory of transformation beyond this point sits in-between the past and the present while involving perceived suspension in time and a nonlinear break of the flow of events. The fact that one was able to continue beyond this point appears to give some sense to the subaltern's life, thus fundamentally structuring her perception of QOL. R26 feels fortunate for breaking through "the past" time-space as a survivor while expressing gratitude for her present situation, although it is evident that her macro self-identity is still work in progress.

It should also be noted that we were interviewing the "survivors"-not all are as lucky as R26 to receive effective communal support exactly when it was needed. It can be figuratively said that subalterns are human beings who can meaningfully bear inhumane living conditions while maintaining occasional cheerfulness. The evidence indicates that subalterns not only manage their lives but also symbolically "structure" it on the verge of impossibility. Consider R22, a 37-old-female who is seen as one of the "untouchables." She explains her situation:
...I did not watch a single movie in a cinema hall in my 30 years of life. I don't go out of this place [village] for any reason than attending relatives' marriages in sum- mer. I have no hope whatsoever of coming out of this agony. How will it happen? We have no skills, we come from a lower caste, and we are not educated. Who will give us a dignified job? Permanent income is just out of the question. In a rainy sea- son, our work stops-the income is reduced. Sometimes the water of this river floods my house. We have to run out for shelter and save our stuff. That time I feel why God has given us this life? This dog has a better life than our lives.

In the capacity of the observers of this group of subaltern consumers, we maintain no illusion regarding the extreme toughness of their living conditions. In fact, in most cases, the conditions exceed the most imaginable boundaries of "tough life." Chronotopefication helps with maintaining life in these conditions where pain appears to be normalized and where the inconceivable struggle for life and everyday difficulties ranging from hunger to a de-dignifying lack of basic utilities to labor exploitation is prevalent (Jagadale et al., 2018). The prolonged burden of hard life may disintegrate hope for some future relief. Nevertheless, chronotopefication creates suspension while enabling subalterns to compact prolonged hard times into narrow perceptual 
periods while zooming into happy microevents, which seem to last for eternity. Yet, there seems to be no end to difficulties:

Whatever I earn, I have to spend on my ailing husband. He has paralysis; he is physically incapacitated. You tell me if there is any hope in such condition. My age is 65 years. I worked as a laborer throughout my life. I never shied away from any hard work. What did I get in return? More work and just hardship. I pray to God: enough is enough...please stop this by either taking us to you or give us the strength to die. Living is becoming a burden for us. ... Better to die than have this life (R23).

Some researchers define the preference for nothingness over existence as hopelessness (Snyder, 2002). We see it as the manifestation of chronotopefication process at work-the future time-space of "no pain" is being brought into the present. Here, "death" is constructed as a cultural time-space where no burden or pain exists.

On a symbolic scale measuring QOL, where the neutral point is the internationally accepted definition of poverty, these communities would indisputably hit the extreme negative side of the neutral point. Why is this the case? Livability theory suggests that such extremely low QOL is simply a consequence of the lack of material resources. Hence the solution would be an increase in income or an administration of some social benefits. The capabilities theory would see it as a lack of skills and capabilities, advising an increased focus on upskilling, training, and education. The dignity perspective emphasizes the lack of dignity (Jagadale et al., 2018). We see the situation as more than the lack of all the aforementioned resources combined. Chronotopefication structures the meaning of an extra benefit (e.g., money, gift, training, job opportunity) granted to subalterns: something that supposedly should boost their QOL may still end up denigrating them (Vikas et al., 2015) if it is done to affirm their subaltern/caste position. R9 emphasized this apparent paradox:

Many a time I experienced that shopkeeper does not show us the best sarees we see on mannequins. They would assume us as from the lower strata, and therefore dispensable customers. Many a time during marriage shopping they would force us to buy lower quality stuff which we do not wish [because it would] display our poverty. However, it is all about our caste; we realize that. Many shopkeepers do not want to entertain us. They think we cannot buy their goods.

In the narratives such as the above quote, we see evidence of un-dignifying disrespect toward these consumers in a range of consumption settings. Interestingly, in Indian rural settings, the sociocultural system drives the economic system: subalterns' input, irrespective of its nature (e.g., money, labor, skills, and communication), is consistently devalued due to caste hierarchy perceptions. Our respondents narrate how other market actors (local landowners, retailers) would discriminate them. Goods, payments, or deals offered to subalterns are either substandard or limited. R4 confided that when he bought an expensive shirt, the higher caste people in his village doubted its legitimacy: where would he get the money from, if not by stealing? From the subalterns' perspective, another unit of a resource (e.g., money or capability) might expand the volume of "disrespected resources," thus adding nearly nothing to QOL. Subalterns yearn the future of recognition, dignity, and respect. By respect, we do not mean a kind of affection in social settings, but something that would show in how subalterns' value-creating 
input (e.g.,, labor or a consumption act) is treated within the market system in terms of equal value or recognized worth provided in exchange.

Nevertheless, chronotopefication helps subalterns to delineate some aspects of their lives as positive. Consider R5, a 30-year-old female of the Sonkar caste. Traditionally, Sonkars are pig farmers considered as untouchables within the Hindu caste system. R5 lived in Mumbai for a short time, where her father worked as a driver. Marriage brought her to the current village in the Mirzapur district. The household consists of R5, her husband, and their six children. She now has a pucca house for a dwelling. Her husband sells vegetables on a cart in the nearby town, and she works as a casual agricultural laborer. Her children do not go to school. Diseases such as diarrhea are common. The partial cost of constructing her house has led to a costly debt (at 5\% per month) from the Thakur and Brahmins (the highest caste groups) of the adjoining village. The creditors started using abuse and intimidation for extracting the debt. Yet, R5 says:

Maintaining life itself is best for life. However, we have faced so many hardships. There is a chance that we will get something in the future. Till now, whatever is there is right, but maybe if God wishes, there might be good days in the future and maybe that life will be good.

Subalterns are happy to hold on to their lives. Although they live with hope, this hope is not a totalistic hope for a positive future, as imagined by Snyder et al. (2002). Rather, it is a hope to be able to maintain life as well as some chance to attain some good days (e.g., respect or deserved recognition). In subaltern narrations, the future is not considered to be the linear continuation of time springing from the present. In contrast, it is the time-space of a collection of "good" days, which would allow subalterns perceptively focused enjoyment. Subalterns dwell in these "islands" of positivity within the imagined distant future.

\section{2 | Futurization of well-being}

The striking similarity in the subalterns' narratives is the careful avoidance of dwelling on present or past problems. When asked about their life, the focus of their narratives tends to switch to the "future" time-space. When reflecting on how they live, subalterns tend to refer to very diverse views of the distant future, which in most cases informed and structured by the past. Consider R4 of the Chamar caste, in his twenties, who is a casual laborer. Previously trying his luck in a big city like Mumbai for a while with his father, he now prefers to stay in the village. $\mathrm{R} 4$ reflects on the way he sees his life:

I keep working on building a future. My thinking is always that I keep thinking forward together with my family. I never think of the past, and whatever is gone, I do not think of, I only look into whatever is coming. We are four brothers, one sister, and parents. I want to live life with everyone together. I always have "hi-fi" thinking, even though I was born in a small, low-income family, but it does not matter. I think of big things, to whatever extent I will run for the future, whether in the past we wore dhoti-kurta (i.e., a local shirt), worked as a bonded laborer does not bother me. I will not be in the same bondage. I want to be independent and work hard for that. I want to earn money based on my work. This is my thinking. 
Despite being expressed in simple words, R4's narrative is not a straightforward one. It is a succinct example of subalterns' QOL perception: past-shunning, future-oriented, agency-driven, proactive, un-egoistic, and highly optimistic. Although the resources are meager, there appears to be no mention of current income or material resource accumulation being an important factor. It appears to be more about future potential to be attained, while the past is used as a baseline. In other words, when reflecting on their state of life, subalterns do not dwell in the past (e.g., bonded labor in this case) but use the past as a gauge of progress toward desired future. Moreover, for them, expected future improvements would not be effective is they were just for a single individual. Rather, all members of the household must benefit from it. Other respondents, for example, R13 and R14 who are a landless Muslim couple with three young children, express a similar sentiment:

\begin{abstract}
A good life should be like-there is pleasure of everything, comfort; there is love among everyone; children get to study, eat well according to their wish; there is no shortage of anything or discomfort. That will be the best, according to me. See, we have always been in poverty. Till now, we have never eaten with independence, worn clothes with independence, never stayed with independence, could not educate our children.
\end{abstract}

F13 and R14 dream of a very modest future. This is a "future" that affords some choice. The past has been too restrictive for them-they were excessively restricted by the "shackles" of poverty and the caste system. For them, well-being means gradual release from these shackles, one-by-one, in all areas and aspects of daily life. This is as though their human "soul" screaming from within them: "just allow us to prove our future potential." Such an attitude in itself appears to be a means of happiness to them. Researchers talk about a process of specific chronotope-building called "futurization" (Sircova et al., 2019). Futurization refers to the continuous construction of a multiplicity of imaginings about a distant future that is full of opportunities, while at the same acting as though these images are true.

Subalterns tend to construct simple but clear visions of their desired future. For example, for R4, the vision is a stable workplace devoid of exploitation and de-dignifying bondage, while for others, it could simply be to have at least some choice in selecting what to eat or dress. For affluent consumers, futurization is linked to the major issue of a time trade-off: how much of present comfort needs to be sacrificed to reach a better/sustainable future (Sircova et al., 2019). If for affluent consumers, futurization implies a possible reduction of well-being, for subalterns, it is quite the opposite: any effort, action, or cost that moves them toward desired future adds to their happiness. Hence, the nature of subaltern futurization is completely different: discomfort is so ubiquitous that any sacrifice that might lead to the desired future may, in fact, increase rather than decrease their well-being. Also, there appears to be complete openness to uncertainty that a future might entail. We observe that subaltern futurization does not involve typical emotions of fear or risk aversion. Rather, there is a sense of welcoming and embracing future uncertainty in a very optimistic manner.

\title{
4.3 | Well-being as communal time-space attribution
}

I think that I will work and earn money to bear the expenses of my family...and take care of everyone. This stays my thinking, and that is why whatever work 
comes, I come forward. Whatever work comes, I will not leave, I will do the work, however much work it may require. I do not shy away from any work, be it soil tilling work, weeding work, work in offices involving writing. I am there for all types of works. People shy away from work, but if one does not work, what will we get? If I do not work, will I get anything? If food is here, but we do not take it up to eat, it will not reach our stomachs. If I do not work from where will I get the money? I want to maintain all my family through my work (R2).

Subalterns' well-being involves family members, extended family, and community. The quote above exemplifies communal devotion and the lack of individualism in subaltern narratives. R2 expresses willingness to work for the well-being of all family members. Bakhtin (1981) argued that chronotopes are symbols of the community since communal sense-making is needed to build self-identity. In addition, Bakhtin emphasized the notion of "outsideness"outsiders would be unable to participate in the construction of time-space perceptions of closely related community (Johnston, 2002). As outsiders, most analysts and observers react to the subaltern dilemma from the prism of gifting, donating and material help. However, subalterns' chronotopefication specifically eschews passive receivership. The narratives tell a story of engagement, resilience, and willingness to work, representing the narrator's "insideness." Within the subaltern's insideness chronotopes, well-being improves only if requisite resources are earned through work in a dignified way. Communal chronotopefication reveals that subalterns would perceive donations or charity as an affirmation of their helplessness and vulnerability. This is exactly something they try to avoid.

Theory predicts that people with low well-being would attribute their low QOL to their agency and personal failures (Schwarz and Clore, 1983). Besides, theory predicts that they would expect such patterns to persist in the future. The evidence we see tells a different story. Subalterns partially attribute their dire situation to their agency: for example, most of them lament about their lack of education. Nonetheless, they do not restrict their well-being to themselves in the present. Rather, their construction of well-being is situated in a broader spatial-temporal dimension: the whole household in the inter-generational space. R9 says:
A good life would be that people stay in a good way, there is a good house, one wears well and there should also be money, and then only we would move ahead. There should also be a house, good clothes and all, and there should be electricity, a fan...where my needs are taken care of.... What else we want in life? The children are there. If they study well, then, they will move forward. There is poverty, so there would be some relief from poverty, would we always stay poor? Sometime god would also see us. Today we accept that we are poor. There are small kids. Tomorrow our kids would also grow, he would also help in some way, and our vehicle would move forward. In a good way, we would spend our life.

The quote above represents a typical subaltern view: to work hard in the near future to enable some members of the household (i.e., younger generation) to "breakthrough." This is an optimistic outlook: it involves all household members supporting each other and working as a unit within this chronotopized intergenerational dynamics. Perceptions that one's past failures would continue indefinitely into the future is absent. Rather, there is a strong hope that education becomes a means of good life, perhaps sometime in the future. R18 narrates: 
You see, had we got the money we would have got our children admitted to a good school, given them good clothes, and also worn good clothes ourselves. We would have been decently able to meet the needs of our children. We only turn towards our poverty and be happy thinking that we may not have it today, but tomorrow when we earn well, we will have. The life is going waiting for this 'tomorrow,' and for how long it will go, only God knows.

Subalterns harbor hope, that is, perceptions of stable pathways, which would certainly take them to attain their goals. However, in contrast to the theory of hope (Snyder, 2002), we find that these pathways are not combined with individual agency. Hope involves the whole family or community. Educating children well and sending them away to urban areas is one of such communal pathways:

I have been in this work for the last 40 years. I am happy for myself but do not want my children and grandchildren here. They should leave this village and settle somewhere in a city where they would get respect. Here some people do not drink water offered by us. In cities, this will not happen. It would be possible only if they shift to cities. I work hard so that they get an education and then migrate (R24).

The existence of definite pathways, light at the end of the tunnel, creates positive hope as well as strong excitement. This pathway appears to be a sure thing: subalterns can see that some others by shifting to a different setting where education is valued could transform their lives. For positive well-being, people need to see such effective effort-outcome relationships. The caste system, in addition to its social meaningfulness and rigid hierarchical structure, tends to paralyze effort-outcome links: whatever subalterns do, their effort is not going to be met with valuable appreciation. Hence, they search for milieus, perhaps economically and socially egalitarian, in which stable effort-outcome mechanisms exist. From a macro perspective, it is about knowing that ultimate justice exists within the marketing system (Kadirov, 2018). This perception, in itself, regardless of people engaging in them, tends to enhance the perception of well-being. This is evident in most narratives: subalterns excitedly talk about the others' transformed lives who followed known pathways to the "bright" future. They feel that there is hope:

My son was getting educated in the local school. I encouraged him. You know he got training in computers!!! He knows so many things. Recently he got a job with the Big-Bazaar. He is so much educated and learned and earns. He spends a lot of money on dresses, mobile phones. He recently got an LED television-it hangs from the wall (beams with a radiant pride). He also recently got an AC and an Iphone, which costs 55,000!! (R28)

Vivid articulations of the future provide for a device of escape from excruciating precarity and culturally deformed markets. For example, R4 could conveniently look through the prospect-less present to construct a utopian future that promises an escape. The same reflections are also heard from R13 and R14. Thus, the participants did not lose hope when their daily existence is at stake: they realized that they were still better off than many. As did many participants, R4, as an example, expressed a mature sense of futurization, one that cannot be measured precisely by any metrics or inferred evidence. 


\section{5 | PROPOSED FRAMEWORK}

Subaltern consumers, who live in abysmally low-quality life conditions (Vikas et al., 2015; Khare and Varman, 2016, 2017; Jagadale et al., 2018), are involved in existential sense-making involving the chronotopefication and futurization processes. These processes ensure that QOL is ongoing dynamic construction, a complex fusion of chronotopes that arise as a combination of sociocultural spaces with temporal points. Life beyond the limits of humanly existence is aggravated through de-dignifying disrespect toward subaltern consumers and the market inputs (e.g., consumption, value-creation, labor) they possess. This makes subalterns bend the otherwise linear flow of time by (a) compressing prolonged negative experiences into dense chronotopes, and (b) dwelling into or extending positively experienced events.

Subalterns' QOL chronotopefication is augmented with futurization. Vivid imaginings of the future have a dimension of "communality" (Hofstede, 1980) that is inclusive of their families and extended families. They imagine exciting future potentialities, for the sake of which they would be willing to bear current/past discomforting experiences. Notwithstanding, subaltern consumers, in their narratives, do not feign any fear for an unknown and uncertain future, while they embrace whatever comes their way. Such futurization does not entail passivity. Their narratives affirm the faith in their communal agency to get where they want to be. This is not without some reservations for not being educated enough, a pathway to achieve the desired vision. Subaltern imagination and hopefulness related to well-being in the distant future have a spatial-temporal dimension: household and intergenerational space. The effort-outcome relationship is negatively skewed against them, where the dominance of sociocultural institutions like the caste system works to paralyze this relationship. It forces subalterns to look for alternative spaces where they can transform their lives. Overall, this research finds that:

1 chronotopefication and futurization are defining processes of subaltern consumers' construction of QOL perceptions;

2 subalterns' sacrifices, efforts, and costs, however painful they may be, are perceived as QOL enhancing from the prism of chronotopefication and futurization; and

3 subaltern consumers chronotopize and futurize QOL for the whole extended household within the inter-generational temporal space.

The findings, as mentioned above, are the foundation of an alternative QOL framework we propose in this research. The main principles of this framework, which we call QOL as chronotopefication and futurization framework (QOL-CFF), are presented in Table 2.

The proposed framework emphasizes the role of chronotopefication and futurization processes in the subaltern construction of QOL perceptions. The conventional QOL perspectives are isolationist: they emphasize the impacts of either temporal (Heidegger, 1996) or spatial factors in isolation. QOL-CFF emphasizes fusion in chronotope-building, that is, holistic timespace sense-making. Most QOL researchers incorporate the time dimension into their models in a mechanistic way, assuming that it has a uniform and linear flow from past to present to future. QOL-CFF maintains the dynamism assumption: it stresses changeable, malleable, nonlinear and asymmetric characteristics of temporality. The conventional perspectives focus on future orientation (Trommsdorff, 1983) as a factor that influences well-being perceptions. In contrast, QOL-CFF posits, based on the presented evidence, that the construction of QOL by subalterns is futurized through the continual emphasis of positive future over the negative past. Whereas the conventional perspectives assume a positive linear effect of an extra resource on 
TA B LE 2 QOL as chronotopefication and futurization framework

\section{Conventional QOL conceptualizations}

Linear effect:

An increase in resource supply increases QOL of the poor in proportion with the magnitude and importance of the resource.

Outcome-oriented (outsideness):

QOL is largely defined by what outcomes are generated for the poor: the powerful actors or donors control the process.

\section{Isolationist:}

QOL perceptions depend on different spatial factors as well as temporal factors, while space and time are kept conceptually isolated from each other.

Mechanistic:

QOL assessments involve the time factor that is assumed to be uniform, linear and symmetric.

Individualistic:

QOL is an individual perception.

Future orientation:

People who have long-term thinking and anticipate future changes tend to have high QOL.

\section{QOL as chronotopefication and futurization}

Symbolic effect:

Chronotopefication may transform a resource increase into a symbolic act in the context of castebased relations, hence leading to the paradoxical reduction in QOL.

Input-outcome oriented (insideness):

Subalterns construct communal, transparent and stable input-outcome pathways as part of chronotopefication: subalterns control the process.

Fusion:

QOL perceptions represent a chronotope, a set of time-space constructions that emerge via chronotopefication process.

Dynamic:

QOL perceptions involve temporality constructions that are changeable, nonlinear and asymmetric.

Communitarian:

QOL is an interactive communal and intergenerational construction.

Futurization:

Subalterns construct QOL in discourse and action through imagining a "positive future" in reference to "negative past".

Progress toward future:

Current efforts and sacrifices are QOL enhancing since they move subalterns closer to their construction of "future."

Abbreviation: QOL, quality-of-life.

QOL perceptions (Diener and Biswas-Diener, 2002), QOL-CFF focuses on the symbolic effect of a resource granted. For example, the reception of an extra resource that affirms subalterns' inferior caste status within exploitative caste relations may further add to the misery of subalterns rather than enhancing their living conditions.

The conventional perspectives consider current difficulties and struggles as a price to be paid currently for a better future consistent with a theory of future discounting (Broome, 1994; Ramos et al., 2013) while QOL-CFF indicates subalterns' interpretation of current "agonies" as the progress toward positive future. Hence, current problems or difficulties may not be seen as QOL degrading on default. To the contrary of conventional assumptions (Ahuvia, 2002), QOL may not be individualistic, at least as far as the QOL of subalterns is concerned. From the QOLCFF perspective, subaltern consumers are communal: for them, a better life is not one that is isolated from their kith and kin. Their QOL perceptions refer to a new level of collectivity: individual sacrifices for the collective are perceived positively. Finally, the conventional perspectives assume QOL perception to be dependent on outcomes created for the poor. Hence, these perspectives are outcome-oriented (Sirgy, 2011). In contrast, QOL-CFF focuses on input-outcome 
relationships (Jagadale et al., 2018): subalterns' outcomes, to be perceived worthy for enjoyment, must be generated through worthy subaltern inputs.

\section{DISCUSSION AND IMPLICATIONS}

This investigation contributes to the body of existing QOL research concerning impoverished and subaltern consumers as well as communities in four ways. First, this research offers an alternative constructivist interpretation of QOL. It shows that QOL is structured as a set of multiple chronotopes arising via the processes of chronotopefication and futurization. In doing this, this research introduces the new concepts of subaltern chronotopefication and futurization, which were not discussed in the extant QOL research. Perhaps, future research would be needed to show if these processes apply to other consumer segments or cohorts. Second, this research situates the temporal dimension (in combination with the spatial dimension) at the heart of QOL perception. Differing from the previous research, time is not assumed as an implicit uniform progression from past to present to future. It is argued that meanings of time are the very structural element out of which QOL perception emerges. Third, in contrast to the mainstream QOL research approach that examines well-being as an individual cognitive process, this research reveals the communal dimension of subaltern QOL perception. Finally, this research offers the QOL-CFF framework to integrate findings into a single conceptual scheme.

\section{1 | Conceptual differences}

The concepts of chronotopefication and futurization are conceptually distinct from the notions of future orientation, hope, and optimism. Future orientation refers to planning for the future or being able to predict the possible future (Sirgy, 2012). The future orientation perspectives assume "time" to be outside of human cognition. Distinctively, chronotopefication is devoid of linear planning (in the Western sense) and anticipation of the future. It refers to processes of cognitive construction of time-space imaginings, compressing and extending the temporal dimension, and infusing time with ideological and sociocultural meanings. Futurization refers to cognitive constructions of the future through vivid imagination and practices which involve acting according to these images. In general, chronotopefication and futurization involve bringing "time" into cognition and changing its meanings according to circumstances.

Hope theory defines hope as a motivational factor that helps to achieve positive goal-related outcomes by activating pathways and agency thoughts (Snyder, 2002). Hope is seen not only to be individualistic but also to be subject to uniform temporal unfolding in the context of the sequences of pre-event, event, and learning (post-event) (Snyder, 2002; Snyder et al., 2002). Moreover, hope is seen to be part of the nomological network of well-being (Snyder et al., 2002; Bailey et al., 2007; Ciarrochi et al., 2015; Gallagher and Lopez, 2018), thus treating QOL perception and hope to be separate phenomena. Several incommensurable differences exist between hope theory and QOL-CFF (note that the QOL-CFF framework given above covers some aspects of these differences). Although chronotopefication may involve goals, pathways, and agency thinking, these thoughts are seen as integrative elements of subaltern QOL perception. Taking a positivist approach, hope theory claims an association between hope and well-being, whereas QOL-CFF takes a constructivist perspective in arguing that QOL perception is 
constructed via chronotopefication process where hope becomes an integral part of time-space constructions. Moreover, hope within chronotopefication does not have a standard uniform character-its nature changes depending on practices of zooming in/zooming out, compression/extension, outsideness/insideness, and eschewing/dwelling. Furthermore, our investigation indicates that chronotopefication is a communal process. While the Western societies focus on realistic hope (Averill et al., 1990) and in much of Asia it is about harmony with the world (Nisbett and Masuda, 2003), in India hope is part of chronotopes that emerge as a mechanism of enhancing QOL in the backdrop of harsh reality.

Optimism is also related to chronotopefication and futurization. Research (Seligman, 1991; Diener and Seligman, 2004; Scheier and Carver, 1993) refers to optimism as a goal-directed process of distancing away from negative outcomes and moving toward positive outcomes. The same assumptions of individualism, uniform time, and separateness underlie the concept of optimism. In contrast, futurization is a communal time-space construction that integratively reifies QOL perception. Futurization is the creation of a chronotope that fuses positive and negative events into a coherent unity, and it is inherently integrated into ongoing practices. This research shows that subalterns do not distance themselves from negative outcomes-rather, they embrace them to be able to create relevant meanings.

The existing research discusses the relationship between aspiration types (e.g., extrinsic versus intrinsic) and well-being (Kasser and Ryan, 1993, 2001). Research shows that intrinsic aspirations (e.g., affiliation, enjoyment, community feeling) are positively associated with wellbeing, while extrinsic aspirations (e.g., material or financial success, social recognition) may not enhance well-being to the same degree (Kasser and Ryan, 2001). Our research shows that chronotopefication involves a nonlinear fusion of aspirations. Subalterns are constantly involved in a kind of extrinsic aspiration related to survival. Kasser and Ryan (2001) assume that people could easily switch between types of aspirations, while subaltern consumers do not possess this luxury. Although it may sound illogical to say that subalterns may intrinsically enjoy "surviving," our research shows that subalterns are skillful in deriving the intrinsic from the extrinsic (focused, dwelled, extended enjoyment of a positive event reflected in an extra income or a social token of respect). In this sense, chronotopefication fuses intrinsic aspirations into extrinsic ones through the creation of holistic QOL perception.

Our findings support the proposition that access to markets and marketing institutions is not unconditional (Fuller, 1989; Ray, 2011; Roy, 2012; Thorat and Newman, 2015). Chronotopefication and futurization underscore the deep mediating power of traditional sociocultural institutions. The inequalities created by neo-liberal discourses hinder the process of equal market participation (Thorat and Newman, 2015) and thus, hamper overall QOL. Subaltern consumers are walking the tight rope of attaining equal market participation mediated by conventional primordial institutions. A decline in reciprocity (Varman and Belk, 2008) is accompanied by the monetization of reciprocal exchanges (Jagadale et al., 2018). Moreover, the decline of reciprocity denotes changes in social relationships (Varman and Belk, 2008). There is an ongoing transition from the social-moral worlds to the market economy, and it has given an opportunity, albeit conditional, to participate in larger economic discoursedriven markets. Chronotopefication is a type of such adaptive discourse. This intrinsic versus extrinsic connectedness of spatial-temporal relationships approximates the subjective construction of a symbolic world that is at the base of most market-based narratives. Subaltern consumers' narrative texts are not only composed of a sequence of diegetic events but also the construction of a particular fictional world of both objective material and subjective enjoyment possibilities. 


\section{2 | Consumer affairs implications}

Within subsistence marketplaces, involvement in marketing practices should be deeply ingrained with the purpose of social good, that is, enhancing the welfare of communities and individuals (Viswanathan et al., 2009, 2019). This research highlights the need for a microlevel, situated, authentic understanding of QOL experiences in subsistence marketplaces, not only required for businesses (Viswanathan et al., 2009), but also for consumers, active subsistence marketplace agents, to deeply understand the sources of their own well-being. Acting in the capacity of "consumer-entrepreneurs" (Viswanathan et al., 2010; Venugopal et al., 2015), subaltern consumers turn to market-based storytelling to reorganize themselves around their own chronotopefication meanings and discover the positive in the face of negative/inhumane circumstances. Jagadale et al. (2018) suggested creating marketing systems with political and economic controls in the hands of subaltern consumers. We further this argument and suggest that policy efforts should be directed toward revitalizing the moral as well as social good economy (Litt et al., 2000; Viswanathan et al., 2009) through the use of the proposed framework of QOLCFF. The framework highlights principles that are distinct to the mainstream logic of wellbeing thinking. Specifically, the consumer's personal input toward enhancing their own and community's well-being appears to be more important than the "outcomes" created for them. This insight inspires a renewed understanding of the subsistence marketplaces axiom of "instrumental versus developmental outlook" (Venugopal and Viswanathan, 2017, p. 349). While eschewing the instrumental outlook, that is, the idea that well-being concerns can be used as a means for profit-making, our research highlights the need for developing subalterns' capacity to actively participate in welfare enhancement. Such participation can be channeled through such practices as a complex program to promote entrepreneurial self-efficacy (Venugopal et al., 2015). This insight is also in line with the suggestion that development interventions cannot be successful without nurturing adaptable, resilient, and knowledgeable consumers in subsistent marketplaces (Abdelnour and Branzei, 2010). Enabling the subsistence consumer's input in the marketplace can be in the form of opportunities for earning dignified income and outlets for respectable spending so that resources channeled to subalterns are not felt as de-dignifying (Vikas et al., 2015). In general, better understanding subaltern chronotopes would allow enabling vibrant moral-economic systems of fair participation (Layton, 2011; Kadirov, 2018).

Considering pervasive poverty-ridden, exploitative, and status-based settings (Hill, 2016), this research is an attempt to answer multiple calls for embracing a bottom-up approach to explore unheard voices of subsistence consumers (Chambers, 1995; Peterson and Ekici, 2007; Viswanathan et al., 2012; Venugopal and Viswanathan, 2017). While giving precedence to the impoverished consumer's constructions, assumptions, life theories, and realities (Hundeide, 1999), this research opens several possibilities for societal institutions including businesses, to incorporate in their strategies the alternative QOL framework proposed in this article. Public policymakers may note that despite participation difficulties, subalterns take marketbased exchanges as an important mode of provisioning. This ensures that market-based activities remain vibrant (e.g., communal institutions like self-help-groups). Public policymakers must ensure that effective socioeconomic and political-institutional frameworks are built taking into account specific subaltern QOL perceptions.

\section{ACKNOWLEDGMENT}

We thank Debojyoti Chakraborty, doctoral candidate at School of Business, University of Connecticut for his initial support in the fieldwork of this project. 


\section{REFERENCES}

Abdelnour, S. and Branzei, O. (2010) Fuel-efficient stoves for Darfur: the social construction of subsistence marketplaces in post-conflict settings. Journal of Business Research, 63(6), 617-629.

Ahuvia, A.C. (2002) Individualism/collectivism and cultures of happiness: a theoretical conjecture on the relationship between consumption, culture and subjective well-being at the national level. Journal of Happiness Studies, 3(1), 23-36.

Ahuvia, A.C. (2005) Beyond the extended self: loved objects and consumers. Journal of Consumer Research, 32 (1), 171-184.

Alborz, A. (2017) The nature of quality of life: a conceptual model to inform assessment: the nature of QoL. Journal of Policy and Practice in Intellectual Disabilities, 14, 15-30.

Ansari, S., Munir, K. and Gregg, T. (2012) Impact at the 'bottom of the pyramid': the role of social capital in capability development and community empowerment. Journal of Management Studies, 49(4), 813-842.

Askegaard, S. and Eckhardt, G.M. (2012) Glocal yoga: reappropriation in the Indian Consumptionscape. Marketing Theory, 12(1), 45-60.

Averill, J.R., Catlin, G. and Chon, K.K. (1990) Rules of Hope. New York: Springer-Verlag.

Backer, E. and Weiler, B. (2018) Travel and quality of life - where do socio-economically disadvantaged individuals fit in? Journal of Vacation Marketing, 24(2), 159-171.

Bailey, T.C., Eng, W., Frisch, M.B. and Snyder, C.R. (2007) Hope and optimism as related to life satisfaction. The Journal of Positive Psychology, 2(3), 168-175.

Baker, D.A. and Palmer, R.J. (2006) Examining the effects of perceptions of community and recreation participation on quality of life. Social Indicators Research, 75(3), 395-418.

Bakhtin, M.M. (1937) Forms of time and of the chronotope in the novel: notes toward a historical poetics. In: Narrative Dynamics: Essays on Time, Plot, Closure, and Frames. Columbus: Ohio State University Press, pp. $15-24$.

Bakhtin, M.M. (1981) The Dialogic Imagination. Austin: University of Texas Press.

Batra, R., Ahuvia, A. and Bagozzi, R.P. (2012) Brand Love. Journal of Marketing, 76(2), 1-16.

Bearden, W.O. and Wilder, R.P. (2007) Household life-cycle effects on consumer wealth and well-being for the recently retired. Journal of Macromarketing, 27(4), 389-403.

Belk, R.W. (1999) Leaping luxuries and transitional consumers. In: Batra, R. (Ed.) Marketing Issues in Transitional Economies. Boston, MA: Springer, pp. 39-54.

Belk, R.W. and Ghoshal, T. (2017) The Kafka quagmire for the poor in India. Journal of Marketing Management, 33(17-18), 1559-1569.

Bemong, N., Borghart, P., De Dobbeleer, M., Demoen, K., De Temmerman, K. and Keunen, B. (2010) Bakhtin's Theory of the Literary Chronotope: Reflections, Applications, Perspectives. Gent, Belgium: Academia Press.

Beteille, A. (2015) The peculiar tenacity of caste. In: Deshpande, S. (Ed.) The Problem of Caste. New Delhi: Orient Blackswan, pp. 53-62.

Biswas-Diener, R. and Diener, E. (2001) Making the best of a bad situation: satisfaction in the slums of Calcutta. Social Indicators Research, 55(3), 329-352.

Bowler, S. and Segura, G. (2011) The Future is Ours: Minority Politics, Political Behavior, and the Multiracial Era of American Politics. Washington, DC: CQ Press.

Braun, V. and Clarke, V. (2006) Using thematic analysis in psychology. Qualitative Research in Psychology, 3(2), 77-101.

Broome, J. (1994) Discounting the future. Philosophy \& Public Affairs, 23(2), 128-156.

Burroughs, J.E. and Rindfleisch, A. (2002) Materialism and well-being: a conflicting value perspective. Journal of Consumer Research, 29, 348-370.

Carter, F.S. (1996) A test of the validity of the "developing country" analogy for the African American community. Journal of Macromarketing, 16(1), 25-51.

Chambers, R. (1995) Poverty and livelihoods: whose reality counts? Environment and Urbanization, 7, 173-204.

Chang, Y. (2019) Does payday lending hurt food security in low-income households? Journal of Consumer Affairs, 53(4), 2027-2057.

Chaplin, L.N., Hill, R.P. and John, D.R. (2014) Poverty and materialism: a look at impoverished versus affluent children. Journal of Public Policy \& Marketing, 33(1), 78-92. 
Ciarrochi, J., Parker, P., Kashdan, T.B., Heaven, P.C.L. and Barkus, E. (2015) Hope and emotional well-being: a six-year study to distinguish antecedents, correlates, and consequences. The Journal of Positive Psychology, 10 (6), 520-532.

Creswell, J.W. (2013) Qualitative Inquiry and Research Design: Choosing Among Five Approaches. Thousand Oaks, CA: Sage.

Crivello, G. (2015) There's no future here: the time and place of children's migration aspirations in Peru. Geoforum, 62, 38-46.

Cummins, R.A., Eckersley, R., Pallant, J., van Vugt, J. and Misajon, R.A. (2003) Developing a national index of subjective well-being: the Australian unity wellbeing index. Social Indicators Research, 64, 159-190.

Cummins, R.A. and Nistico, H. (2002) Maintaining life satisfaction: the role of positive cognitive bias. Journal of Happiness Studies, 3(1), 37-69.

Daly, J., Kellehear, A. and Gliksman, M. (1997) The Public Health Researcher: A Methodological Approach. Melbourne, Australia: Oxford University Press.

Davidson, C. (2009) Transcription: imperatives for qualitative research. International Journal of Qualitative Methods, 8(2), 36-52.

Day, H. and Jankey, S.G. (1996) Lessons from literature: towards a holistic model of quality of life. In: Renwick, R., Brown, I. and Nagler, M. (Eds.) Quality of Life in Health Promotion and Rehabilitation: Conceptual Approaches, Issues And Applications. Thousand Oaks, CA: Sage, pp. 39-50.

Deci, E.L. and Ryan, R.M. (2008) Hedonia, Eudaimonia, and well-being: an introduction. Journal of Happiness Studies, 9(1), 1-11.

Deshpande, A. (2017) The Grammar of Caste. New Delhi: Oxford University Press.

Diener, E. and Biswas-Diener, R. (2002) Will money increase subjective well-being? Social Indicators Research, 57(2), 119-169.

Diener, E., Lucas, R.E. and Oishi, S. (2002) Subjective well-being: the science of happiness and life satisfaction. In: Snyder, C.R. and Lopez, S.J. (Eds.) Handbook of Positive Psychology. Oxford: Oxford University Press, pp. 63-69.

Diener, E. and Seligman, M.E.P. (2004) Beyond money- toward an economy of well-being. Psychological Science in the Public Interest, 5(1), 1-31.

Diener, E., Suh, E.M., Lucas, R.E. and Smith, H.L. (1999) Subjective well-being: three decades of progress. Psychological Bulletin, 125, 276-302.

Diener, E., Wirtz, D., Tov, W., Kim-Prieto, C., Choi, D.-w., Oishi, S. and Biswas-Diener, R. (2010) New well-being measures: short scales to assess flourishing and positive and negative feelings. Social Indicators Research, 97 (2), 143-156.

Dixon, D.F. (2002) Emerging macromarketing concepts from Socrates to Alfred Marshall. Journal of Business Research, 55, 87-95.

Dreze, J. and Sen, A. (1989) Hunger and Public Action. Oxford: Oxford University Press.

Dreze, J. and Sen, A. (2013) An Uncertain Glory: India and its Contradictions. Princeton, NJ: Princeton University Press.

Dumont, L. (1970) Homo Hierarchicus: The Caste System and its Implications. Chicago: The University of Chicago Press.

Eckhardt, G.M. and Humaira, M. (2012) Globalization, consumer tensions, and the shaping of consumer culture in India. Journal of Macromarketing, 32(3), 280-294.

Ekici, A. and Peterson, M. (2009) The unique relationship between quality of life and consumer trust in marketrelated institutions among financially constrained consumers in a developing country. Journal of Public Policy \& Marketing, 28(1), 56-70.

Erlandson, D.A., Harris, E.L., Skipper, B.L. and Allen, S.D. (1993) Doing Naturalistic Inquiry: A Guide to Methods. Newbury Park CA: Sage.

FAO. 2018 The State of Food Security and Nutrition around the World. Available at http://www.fao.org/state-offood-security-nutrition/en/.

Farrell, J.R. and Hill, R.P. (2018) Poverty research and measurement: making the case for consumption adequacy. Journal of Consumer Affairs, 52(3), 770-791.

Fisk, G. (2006) Envisioning a future for macromarketing. Journal of Macromarketing, 26(2), 214-218.

Fuller, C.J. (1989) Misconceiving the grain heap: a critique of the concept of the Indian Jajmani system. In: Perry, J. and Bloch, M. (Eds.) Money and Morality of Exchange. Cambridge: Cambridge University Press, pp. $33-63$. 
Gallagher, M.W. and Lopez, S.J. (2018) The Oxford Handbook of Hope. New York: Oxford University Press.

Glaser, B. and Strauss, A. (1967) The Discovery of Grounded Theory: Strategies for Qualitative Research. Chicago: Aldine.

Goulding, C. (2005) Grounded theory, ethnography and phenomenology. A comparative analysis of three qualitative strategies for marketing research. European Journal of Marketing, 39(3/4), 294-308.

Guba, E.G. and Lincoln, Y.S. (1989) Fourth Generation Evaluation. Newbury Park, CA: Sage.

Gupta, D. (2015) Continuous hierarchies and discrete castes. In: Deshpande, S. (Ed.) The Problem of Caste. New Delhi: Orient Blackswan, pp. 44-52.

Hayborn, D.M. (2001) Happiness and pleasure. Philosophy and Phenomenological Research, 62(3), 501-528.

Heidegger, M. (1996) Being and Time: A Translation of Sein und Zeit. Albany, NY: SUNY Press.

Hill, R.P. (2002) Consumer culture and the culture of poverty: implications for marketing theory and practice. Marketing Theory, 2(3), 273-293.

Hill, R.P. (2016) Poverty as we never knew it: THE source of vulnerability for most of humankind. Journal of Marketing Management, 32(3-4), 365-370.

Hill, R.P. (2019) Ready for the revolution? Why publishing consumer research is changing. Journal of Consumer Affairs, 53(3), 691-695.

Hill, R.P. and Adrangi, B. (1999) Global poverty and the United Nations. Journal of Public Policy \& Marketing, 18 (2), 135-146.

Hill, R.P. and Dhanda, K.K. (1999) Gender inequality and quality of life: a macromarketing perspective. Journal of Macromarketing, 19(2), 140-152.

Hill, R.P. and Gaines, J. (2007) The consumer culture of poverty: behavioral research findings and their implications in an ethnographic context. The Journal of American Culture, 30(1), 81-95.

Hofstede, G. (1980) Culture's Consequences: International Differences in Work-Related Values. Beverly Hills, CA: Sage.

Hundeide, K. (1999) Four different meanings of being poor. Psychology and Developing Societies, 11(2), 143-155.

Jagadale, S.R., Kadirov, D. and Chakraborty, D. (2018) Tackling subaltern quandary- marketing systems of dignity. Journal of Macromarketing, 38(1), 91-111.

Jaiswal, A.K. and Gupta, S. (2015) The influence of marketing on consumption behaviour at the bottom of the pyramid. Journal of Consumer Marketing, 32(2), 113-124.

Johnston, R.R. (2002) A narrative chronotope. In: Sell, R.D. (Ed.) Children's Literature as Communication. Amsterdam, PA: John Benjamins Publishing Company, pp. 137-157.

Kadirov, D. (2018) Towards a theory of marketing systems as the public good. Journal of Macromarketing, 38(3), 278-297.

Kahneman, D. (1994) New challenges to the rationality assumption. Journal of Institutional and Theoretical Economics, 150(1), 18-36.

Kapuria, P. (2014) Quality of life in the City of Delhi: an assessment based on access to basic services. Social Indicators Research, 117(2), 459-487.

Karnani, A. (2017) The roles of the private and public sectors in poverty reduction. Journal of Marketing Management, 33(17-18), 1585-1592.

Kasser, T. and Ryan, R.M. (1993) A dark side of the American dream: correlates of financial success as a central life aspiration. Journal of Personality and Social Psychology, 65(2), 410-422.

Kasser, T. and Ryan, R.M. (2001) Be careful what you wish for: optimal functioning and the relative attainment of intrinsic and extrinsic goals. In: Schmuck, P. and Sheldon, K.M. (Eds.) Life Goals and Well-Being: Towards a Positive Psychology of Human Striving. Seattle, WA: Hogrefe \& Huber Publishers, pp. 116-131.

Khare, A. and Varman, R. (2016) Kafkaesque institutions at the base of the pyramid. Journal of Marketing Management, 32(17-18), 1619-1646.

Khare, A. and Varman, R. (2017) Subalterns, empowerment and the failed imagination of markets. Journal of Marketing Management, 33(17-18), 1593-1602.

Kurien, C.T. (1994) Global Capitalism and the Indian Economy. New Delhi: Orient Longman.

Kurien, C.T. (1995) Aspects of India's Economy. New Delhi: Orient Longman.

Lal, V. (2001) Subaltern studies and its critics: debates over Indian history. History and Theory, 40(1), 135-148.

Land, K.C., Michalos, A.C. and Sirgy, M.J. (2012) Handbook of Social Indicators and Quality of Life Research. Netherlands: Springer Science \& Business Media. 
Layton, R.A. (2011) Towards a theory of marketing systems. European Journal of Marketing, 45(1/2), 259-276.

Lee, M.S.W. and Ahn, C.S.Y. (2016) Anti-consumption, materialism, and consumer well-being. Journal of Consumer Affairs, 50(1), 18-47.

Lincoln, Y.S. and Guba, E.G. (1985) Naturalistic inquiry. In: Naturalistic Inquiry. Beverly-Hills, CA: Sage.

Litt, J., Gaddis, B.J., Fletcher, C.N. and Winter, M. (2000) Leaving welfare: independence or continued vulnerability? Journal of Consumer Affairs, 34(1), 82-96.

Love, L.L. and Crompton, J.L. (1999) The role of quality of life in business (re) location decisions. Journal of Business Research, 44(3), 211-222.

MacInnis, D.J. and De Mello, G.E. (2005) The concept of Hope and its relevance to product evaluation and choice. Journal of Marketing, 69(1), 1-14.

Martin, K.D. and Hill, R.P. (2011) Life satisfaction, self-determination, and consumption adequacy at the bottom of the pyramid. Journal of Consumer Research, 38(6), 1155-1168.

McCracken, G. (1988) The Long Interview. London: Sage.

Mirzapur. (2019) Government of Uttar Pradesh. Available at: https://mirzapur.nic.in/economy.

Nguyen, T.D. and Nguyen, T.T.M. (2012) Psychological capital, quality of work life, and quality of life of marketers: evidence from Vietnam. Journal of Macromarketing, 32(1), 87-95.

Nisbett, R.E. and Masuda, T. (2003) Culture and point of view. Proceedings of the National Academy of Sciences of the United States of America, 100(19), 11163-11170.

Nussbaum, M.C. (2011) Creating Capabilities: The Human Development Approach. Cambridge, MA: Harvard University Press.

Nussbaum, M.C. and Sen, A. (1993) The Quality of Life. Oxford, England: Clarendon Press.

Patnaik, P. (2006) The State under Neo-Liberalism. New York: Monthly Review. http://mrzine.monthlyreview. org/2010/patnaik100810.html.

Patnaik, U. (2013) Poverty Trends in India 2004-05 to 2009-10. Economic \& Political Weekly, 48(40), 43-58.

Patnaik, P. (2016) Economic liberalization and working poor. Economic \& Political Weekly, 51(29), 47-51.

Peterson, M. and Ekici, A. (2007) Consumer attitude toward marketing and subjective quality of life in the context of a developing country. Journal of Macromarketing, 27(4), 350-359.

Poland, B.D. (2002) Transcription quality. In: Gubrium, J.F. and Holstein, J.A. (Eds.) Handbook of Interview Research: Context and Method. Thousand Oaks, CA: Sage, pp. 629-649.

Press Information Bureau. (2017) Ministry of Statistics \& Programme Implementation. Available at: http://pib. nic.in/newsite/PrintRelease.aspx?relid=169546.

Pulver, S. and Van Deveer, S. (2007) Futurology and futurizing: a research agenda on the practice and politics of global environmental scenarios. In: Amsterdam Conference on the Human Dimensions of Global Environmental Change Earth Systems Governance: Theories and Strategies for Sustainability. Amsterdam, Netherlands: Earth System Governance.

Ramos, D., Victor, T., Seidl deMoura, M.L. and Daly, M. (2013) Future discounting by slum dwelling youth versus university students in Rio de Janeiro. Journal of Research on Adolescence, 23(1), 95-102.

Rawls, J. (1971) A Theory of Justice. Cambridge, MA: Belknap Press of Harvard University Press.

Rawls, J. and Kelley, E. (2001) Justice as Fairness: A Restatement. Cambridge, MA: Harvard University Press.

Ray, R.K. (2011) Bazaar: pulsating heart of the Indian economy. In: Kudaisya, M.M. (Ed.) The Oxford India Anthology of the Business History. New Delhi: Oxford University Press, pp. 3-48.

Rice, P.L. and Ezzy, D. (1999) Qualitative Research Methods: A Health Focus. Melbourne: Oxford University Press.

Roster, C.A. (2015) "Help, I have too much stuff!" extreme possession attachment and professional organizers. Journal of Consumer Affairs, 49(2), 303-327.

Roy, T. (2012) India in the World Economy: From Antiquity to the Present. New Delhi: Cambridge University Press.

Roy-Chaudhuri, H. (2010a) Everyday life of the subaltern consumers: contexts, realities, and issues for marketing. The Marketing Review, 10(3), 259-267.

Roy-Chaudhuri, H. (2010b) Selling 'enjoyment' to subaltern consumers. Economic \& Political Weekly, 45(46), 19-20.

Sandikci, O., Peterson, M., Ekici, A. and Simkins, T. (2016) Development and quality of life in Turkey - how globalization, religion, and economic growth influence individual well-being. Journal of Macromarketing, 36 (3), 304-320. 
Scheier, M.F. and Carver, C.S. (1993) On the power of positive thinking: the benefits of being optimistic. Current Directions in Psychological Science, 2(1), 26-30.

Schembri, S. and Ghaddar, S. (2018) The affordable care act, the Medicaid coverage gap, and Hispanic consumers: a phenomenology of Obamacare. Journal of Consumer Affairs, 52(1), 138-165.

Schwandt, T.A. (1994) Constructivist, interpretivist approaches to human inquiry. In: Denzin, N.K. and Lincoln, Y.S. (Eds.) Handbook of Qualitative Research. Thousand Oaks, CA: Sage, pp. 118-137.

Schwarz, N. and Clore, G.L. (1983) Mood, misattribution, and judgments of well-being: informative and directive functions of affective states. Journal of Personality and Social Psychology, 45(3), 513-523.

Schyns, P. (2000) The relationship between income, changes in income and life satisfaction in West Germany and the Russian Federation: relative, absolute, or a combination of both? In: Diener, E. and Rahtz, D.R. (Eds.) Advances in Quality of Life Theory and Research. Dordrecht, the Netherlands: Kluwer Academic Publishers, pp. 203-207.

Scott, E.L., Agresti, A.A. and Fitchett, G. (1998) Factor analysis of the spiritual well-being scale and its utility with psychiatric inpatients. Journal for the Scientific Study of Religion, 37(2), 314-318.

Seligman, M.E. (1991) P 1991 Learned optimism. New York: AA Knopf.

Seligman, M.E.P. (2011) Flourish: A Visionary New Understanding of Happiness and Well-Being. New York: The Free Press.

Sen, A. (1983) Poverty and Famines. Oxford: Oxford University Press.

Sen, A. (1985) Wellbeing, agency and freedom: the Dewey lectures 1984. Journal of Philosophy, 82(4), 169-221.

Shrivastava, A. and Kothari, A. (2014) Churning the Earth: The Making of Global India. New Delhi: Penguin Viking.

Silverman, D. (2006) Interpreting Qualitative Data: Methods for Analysing Talk, Text and Interaction. California: Sage.

Simsek, O.F. (2009) Happiness revisited: ontological well-being as a theory-based construct of subjective wellbeing. Journal of Happiness Studies, 10(5), 505-522.

Sircova, A., Scharf, A.E., Kennedy, M. and Päivinen, P.R. (2019) Futurization of thinking and behavior: exploring people's imaginaries about the future and futurization. In: Managing Screen Time in an Online Society. Hershey, PA: IGI Global, pp. 219-245.

Sirgy, M.J. (2011) Theoretical perspectives guiding QOL indicator projects. Social Indicators Research, 103(1), $1-22$.

Sirgy, M.J. (2012) The Psychology of Quality of Life: Hedonic Well-Being, Life Satisfaction, and Eudaimonia, Vol. 50 Dordrecht, the Netherlands: Springer Science \& Business Media.

Sirgy, M.J., Widgery, R.N., Lee, D.-J. and Grace, B.Y. (2010) Developing a measure of community well-being based on perceptions of impact in various life domains. Social Indicators Research, 96(2), 295-311.

Snyder, C.R. (2002) Hope theory: rainbows in the mind. Psychological Inquiry, 13(4), 249-275.

Snyder, C.R., Rand, K.L. and Sigmon, D.R. (2002) Hope theory: a member of the positive psychology family. In: Snyder, R.C. and Lopez, S.J. (Eds.) Handbook of Positive Psychology. New York: Oxford University Press, pp. 257-276.

Spivak, G.C. (1988) Can the subaltern speak? In: Carry, N. and Grossberg, L. (Eds.) Marxism and the Interpretation of Culture. Urbana: University of Illinois Press, pp. 271-313.

Staats, S., Armstrong-Stassen, M. and Partillo, C. (1995) Student well-being: are they better off now? Social Indicators Research, 34(1), 93-112.

Strauss, A.L. and Corbin, J.M. (1998) Basics of Qualitative Research. Thousand Oaks: Sage.

Sumner, L.W. (1996) Welfare, Happiness, and Ethics. New York: Oxford University Press.

Thorat, S. and Negi, P. (2005) Reservation and private sector: Quest for equal opportunity and growth. New Delhi: Rawat Publications.

Thorat, S. and Newman, K.S. (2015) Caste and economic discrimination. In: Deshpande, S. (Ed.) The Problem of Caste. New Delhi: Orient Blackswan, pp. 81-88.

Trommsdorff, G. (1983) Future orientation and socialization. International Journal of Psychology, 18(1-4), 381-406.

Varman, R. and Belk, R.W. (2008) Weaving a web: subaltern consumers, rising consumer culture, and television. Marketing Theory, 8(3), 227-252. 
Varman, R. and Belk, R.W. (2012) Consuming postcolonial shopping malls. Journal of Marketing Management, 28(1-2), 62-84.

Varman, R. and Costa, J.A. (2008) Embedded markets, communities and the invisible hand of social norms. Journal of Macromarketing, 28(2), 141-156.

Varman, R. and Devi, V. (2018) Dispossessing vulnerable consumers: derealization, desubjectification, and violence. Marketing Theory, 18(3), 307-326.

Varman, R., Skalen, P. and Belk, R.W. (2012) Conflicts at the bottom of the pyramid: profitability, poverty alleviation, and neo-liberal governmentality. Journal of Marketing \& Public Policy, 31(1), 19-35.

Varman, R. and Vikas, R.M. (2007a) Freedom and consumption: toward conceptualizing systemic constraints for subaltern consumers in a capitalist society. Consumption, Markets and Culture, 10(2), 117-131.

Varman, R. and Vikas, R.M. (2007b) Rising markets and failing health: an inquiry into subaltern health care consumption under neoliberalism. Journal of Macromarketing, 27(2), 162-172.

Veenhoven, R. (1991) Is happiness relative? Social Indicators Research, 24(1), 1-34.

Veenhoven, R. (1995) The cross-national pattern of happiness: test of predictions implied in three theories of happiness. Social Indicators Research, 34, 33-68.

Venugopal, S. and Viswanathan, M. (2017) The subsistence marketplaces approach to poverty: implications for marketing theory. Marketing Theory, 17(3), 341-356.

Venugopal, S., Viswanathan, M. and Jung, K. (2015) Consumption constraints and entrepreneurial intentions in subsistence marketplaces. Journal of Public Policy \& Marketing, 34(2), 235-251.

Vikas, R.M. and Varman, R. (2007) Erasing futures: ethics of marketing an intoxicant to homeless children. Consumption, Markets and Culture, 10(2), 189-202.

Vikas, R.M., Varman, R. and Belk, R.W. (2015) Status, caste, and market in a changing Indian Village. Journal of Consumer Research, 42(3), 472-498.

Viswanathan, M. (2017) What the subsistence marketplaces stream is really about: beginning with micro-level understanding and being bottom-up. Journal of Marketing Management, 33(17-18), 1570-1584.

Viswanathan, M., Elaydi, R., Gau, R. and Christensen, L.J. (2019) Subsistence marketplaces: challenges and opportunities. Journal of Public Policy \& Marketing, 38(1), 36-41.

Viswanathan, M., Seth, A., Gau, R. and Chaturvedi, A. (2009) Ingraining product-relevant social good into business processes in subsistence marketplaces: the sustainable market orientation. Journal of Macromarketing, 29(4), 406-425.

Viswanathan, M., and Rosa, J.A. (2007) Product and market development for subsistence marketplaces: Consumption and entrepreneurship beyond literacy and resource barriers. Advances in International Management, 20(1), 1-17.

Viswanathan, M., Sridharan, S. and Ritchie, R. (2010) Understanding consumption and entrepreneurship in subsistence marketplaces. Journal of Business Research, 63(6), 570-581.

Viswanathan, M., Sridharan, S., Ritchie, R., Venugopal, S. and Jung, K. (2012) Marketing interactions in subsistence marketplaces: a bottom-up approach to designing public policy. Journal of Public Policy \& Marketing, 31(2), 159-177.

Weisskopf, T.E. (2004) Affirmative Action in the United States and India: A Comparative Perspective. New York: Routledge.

Wilkie, W.L. and Moore, E.S. (1999) Marketing's contributions to society. Journal of Marketing, 63, 198-218.

Wirtz, K. (2016) The living, the dead, and the immanent: dialogue across Chronotopes. HAU: Journal of Ethnographic Theory, 6(1), 343-369.

How to cite this article: Jagadale SR, Roy-Chaudhuri H, Kadirov D. Quality-of-life as chronotopefication and futurization: Subsistence consumer experiences in India. J Consum Aff. 2020;1-28. https://doi.org/10.1111/joca.12309 